\title{
Analisis Kepuasan Mahasiswa terhadap Kualitas Website Sistem Informasi Akademik Universitas Islam Negeri Alauddin Makassar dengan Menggunakan Metode Structural Equation Modeling
}

\author{
Adnan Sauddin \\ Universitas Islam Negeri Alauddin Makassar, adnan.sauddin@uin-alauddin.ac.id \\ M. Ichsan Nawawi \\ Universitas Islam Negeri Alauddin Makassar,m.ichsannawawi@gmail.com \\ Yanti Kumaladewi \\ Universitas Islam Negeri Alauddin Makassar, kumaladewiyan@gmail.com
}

\begin{abstract}
ABSTRAK, Website merupakan penyedia layanan informasi yang penting dan dimanfaatkan oleh mahasiswa. Mengetahui kepuasan pengguna merupakan salah satu bentuk evaluasi yang dapat dilakukan. Penelitian ini mengasumsikan bahwa sistem, informasi, interkasi dan layanan memiliki pengaruh terhadap kepuasan pengguna. Dengan menggunakan analisis Structural Equation Modeling Partial Least Square diperoleh hasil penelitian bahwa sistem, interaksi, informasi dan layanan berpengaruh terhadap kepuasan pengguna.
\end{abstract}

Kata Kunci: SEM, SEM-PLS, Satisfaction, Quality of Service, Quality of Information, Webquality

\section{PENDAHULUAN}

Masyarakat dapat mengakses informasi dari berbagai belahan dunia dengan memanfaatkan teknologi informasi. Salah satu hasil perkembangan teknologi adalah terlahirnya jasa penyedia infomasi seperti website atau sistem informasi berbasis web. Informasi dari website dapat diakses dengan mudah oleh masyarakat hanya dengan bermodalkan koneksi internet. di dunia pendidikan, teknologi informasi dimanfaatkan untuk memberikan pelayanan jasa kepada maha-siswa di perguruan tinggi. Pelayanan online yang diberikan terdiri dari berbagai tahapan seperti pendaftaran, jadwal perkuliahan, pengumuman dan lain-lain. Pelayanan pada mahasiswa yang memanfaatkan teknologi informasi dapat mengefisienkan waktu jika dibandingkan dengan pelayanan secara manual. UIN Alauddin Makassar adalah salah satu institut pendidikan yang memanfaatkan teknologi informasi dalam hal memberikan pelayanan informasi melalui media internet yaitu website. Salah satunya adalah bidang akademik dengan menyediakan pelayanan online yang disebut Sistem Informasi Akademik(SIA).
Dengan mengetahui tentang persepsi pengguna, pihak Universitas dapat mengetahui kekurangan yang terdapat pada sistem serta dapat menentukan langkah yang tepat untuk peningkatan indikator pada sistem online.

Beberapa penelitian terkait kepuasan pengguna sistem informasi sebagai salah satu bagian yang layanan dalam suatu perguruan tinggi menyatakan bahwa indicator yang mempengaruhi kepuasan mahasiswa daam memanfaat web sebagai suatu fasilitas layanan diantaranya, interaksi, kualitas informasi [1], [2], [3]. Penelitian dalam hal pemodelan loyalitas pengguna menggunakan metode SEM dan/atau SEM-PLS, bahwa indikator mempengaruhi loyalitas pengguna -secara ringkasannyadiantaranya; faktor internal-diantaranyaKepuasan mahasiswa/pengguna, komitmen mahasiswa dalam pengembangan diri-faktor eksternal dari mahasiswa dikategaorikan dalam dua hal, pertama; lingkungan pergaulan-kualitas lingkungan sosial, integrasi sosial, kedua; lingkungan pemberi layanan-kepercayaan, reputasi, kualitas instruktur, kualitas, administrasi [10],[11].

Berdasarkan uraian tersebut, pertanyaan adalah, bagaimana dengan fasilitas website yang dikembangkah dan telah digunakan di Universitas Islam Negeri Alauddin Makassarapakah telah memenuhi harapan atau kepuasan mahasiswa dari semua dimensi-dimensi layanan? Dari hasil pengalaman peneliti dan rekan-rekan, selama mengikuti dan memanfaat semua fasilitas website di lingkungan Universitas Islam Negeri Alauddin Makassar merasakan manfaat sebagai suatu fasilitas yang pemanfaatannya bersifatakses secara luas (sifat dari websiter) dan berbagai fungsi lainya. keadaan tersebut, yakni 
kondisi yang saya dan teman-teman alami apakah berlaku secara keseluruhan dari seluruh mahasiswa atau tidak. Untuk memahaminya, strukturan equation model sebagai salah satu teknik analisis untuk melihat hubungan antara variable latern dengan indikator-indikator, akan tetapi, karena segala keterbatasan-waktu dan biaya untuk mendapatkan sampel yang cukup besar, peneliti memilih metode SEM-PLS.

\section{TINJAUAN PUSTAKA}

\section{Structural Equation Modeling (SEM)}

Structural Equation Modeling (SEM) merupakan teknik statistik analisis multivariat yang menganalisis pola hubungan antara variabel laten dan indikatornya.[5],[12],[13],[14],[15].

\section{Struktur Data}

Struktur data pada SEM disajikan dalam bentuk matriks. Nilai-nilai dari variabel secara keseluruhan dicatat untuk setiap item, individu atau unit percobaan. Notasi yang digunakan adalah yang merupakan nilai dari variabel ke-k yang diamati pada item ke-j [6]

$\mathrm{X}=\left[\begin{array}{cccccc}x_{11} & x_{12} & \cdots & x_{1 k} & \cdots & x_{1 p} \\ x_{21} & x_{22} & \cdots & x_{2 k} & \cdots & x_{2 p} \\ \vdots & \vdots & & \vdots & & \vdots \\ x_{j 1} & x_{j 2} & \cdots & x_{j k} & \cdots & x_{j p} \\ \vdots & \vdots & & \vdots & & \vdots \\ x_{n 1} & x_{n 2} & \cdots & x_{n k} & \cdots & x_{n p}\end{array}\right]$

\section{Hubungan Rekursif}

Rekursif artinya pengaruh hubungan bersifat satu arah yang ditunjukan dengan tanda panah satu arah [7]

\section{Struqtural Equation Modeling Partial Least Square (SEM-PLS)}

Partial Least Square merupakan teknik alternatif pada analisis SEM yang mengijinkan datanya tidak berdistribusi normal.

1. Inner Model (Model Struktural)

Ppersamaan Inner Model dapat ditulis dengan notasi matriks sebagai berikut:

$$
\kappa=\mathbf{N} \boldsymbol{\kappa}+\mathbf{Y} \mathbf{l}+\varkappa
$$

2. Outer Model (Model Pengukuran)

Model pengukuran dibedakan menjadi dua yaitu:

a. Model Pengukuran Reflektif

Persamaan model pengukuran reflektif terdiri berdasarkan model variabel endogen dan eksogennya dengan persamaan sebagai berikut:

1) Model Pengukuran Reflektif Variabel Endogen

Persamaan matematis model pengukuran reflektif variabel endogen dapat dituliskan sebagai berikut:

$$
\mathbf{y}=\mathbf{T} \kappa+\varepsilon
$$

2) Model Pengukuran Reflektif Variabel Eksogen

Persamaan matematis model pengukuran reflektif variabel eksogen dapat dituliskan sebagai berikut:

$$
\mathbf{x}=\mathbf{T} \mathbf{t}+\boldsymbol{\delta}
$$

b. Model Pengukuran Formatif

Persamaan model pengukuran formatif terdiri dari model variabel endogen dan eksogen dengan persamaan sebagai berikut:

1) Model Pengukuran Formatif Variabel Endogen

Persamaan model pengukuran formatif variabel endogen dapat dituliskan sebagai berikut:

$$
\kappa=\mathbf{O}_{y} \mathbf{y}+\epsilon
$$

2) Model Pengukuran Formatif Variabel Eksogen

Persamaan model pengukuran formatif variabel eksogen dapat dituliskan sebagai berikut:

$$
\imath=\mathbf{O}_{x} x+\varphi
$$

\section{Evaluasi Model}

Evaluasi model dengan pendekatan PLS terdiri atas lima bagian :

1. Uji Validitas Konvergen

Penilaian uji validitas konvergen dengan indikator refleksif dinilai berdasarkan faktor loading indikator yang mengukur konstruk dengan melihat korelasi antara skor variabel laten. Faktor loading dianggap signifikan apabila berkorelasi > 0.7 Rumus korelasi adalah sebagai berikut : 


$$
r=\frac{n \sum_{i=1}^{n} X_{i} Y_{i}-\sum_{i=1}^{n} X_{i} Y_{i}}{\sqrt{\left[n \sum_{i=1}^{n} X^{2}-\left(\sum_{i=1}^{n} X_{i}\right)^{2}\right]\left[n \sum_{i=1}^{n} Y_{i}^{2}-\left(\sum_{i=1}^{n} Y_{i}\right)^{2}\right]}}
$$

2. Uji Validitas Diskriminan (Discriminant Validity)

Uji validitas diskriminan dengan indikator refleksif dinilai berdasarkan cross loading pengukuran dengan konstruk. Untuk menilai validitas diskriminan dapat menggunakan Average Variance Extracted (AVE) dengan rumus sebagai berikut:

$$
A V E=\frac{\sum \lambda_{i}^{2}}{\sum \lambda_{i}^{2}+\sum \operatorname{var}\left(\varepsilon_{1}\right)}
$$

Nilai AVE seharusnya $>0.5$.

3. Uji Reabilitas

Uji reabilitas dapat dilihat pada nilai Composite Reability yang diperoleh dengan rumus:

$$
C R=\frac{\left(\sum \lambda_{i}\right)^{2}}{\left(\sum \lambda_{i}\right)^{2}+\sum \operatorname{var}\left(\varepsilon_{1}\right)}
$$

Nilai CR seharusnya lebih besar dari 0.7 namun nilai 0.6 masih dikatakan reliabel atau dapat diterima.[8]

4. Goodness of Fit

Penilaian goodness of fit menggunakan $Q$ square predictive relevant dengan rumus:

$$
Q^{2}=1-\left(1-R_{1}^{2}\right)\left(1-R_{2}^{2}\right) \ldots\left(1-R_{P}^{2}\right)
$$

Model dikatakan baik apabila nilai $\mathrm{Go} \geq 0.36$

5. Uji Signifikansi Parameter

Untuk menguji signifikansi parameternya SEM-PLS bergantung pada prosedur boostrap dalam pengujian hipotesis [12]. Hipotesis yang digunakan adalah sebagai berikut :

a. Pengujian hipotesis untuk outer model

$$
H_{0}: \lambda_{i}=0 \text { melawan } H_{0}: \lambda_{i} \neq 0
$$

Dengan statistik uji $t$-student dengan rumus sebagai berikut:

$$
t_{\text {hitung }}=\frac{\lambda}{S E(\lambda)}
$$

Kriteria pengujian $H_{0}$ ditolak jika

$$
t_{\text {hitung }}>t_{\alpha / 2}
$$

b. Pengujian hipotesis untuk inner model: variabel laten eksogen terhadap variabel laten eksogen

$H_{0}: \gamma_{i}=0$ melawan $H_{0}: \gamma_{i} \neq 0$

Dengan statistik uji $t$-student dengan rumus sebagai berikut:

$$
t_{\text {hitung }}=\frac{\gamma}{S E(\gamma)}
$$

Kriteria pengujian $H_{0}$ ditolak jika $t_{\text {hitung }}>t_{\alpha / 2}$

c. Pengujian hipotesis untuk outer model: variabel konstruk terhadap indikatornya.

$$
H_{0}: \beta_{i}=0 \text { melawan } H_{0}: \beta_{i} \neq 0
$$

Dengan statistik uji $t$-student dengan rumus sebagai berikut:

$$
t_{\text {hitung }}=\frac{\beta}{S E(\beta)}
$$

Kriteria pengujian $H_{0}$ ditolak jika $t_{\text {hitung }}>t_{\alpha / 2}$ atau

Dengan menggunakan nilai dari $\mathrm{p}$-value, jika $p-$ value $>\alpha, H_{0} \operatorname{ditolak}[9]$

\section{METODOLOGI}

Penelitian ini adalah penelitian survey. Jenis data yang digunakan adalah data kuantitatif dengan menggunakan kuesinoer[2]. Populasi sebanyak 20.434 dan sampel yang digunakan sebanyak 393 dengan teknik eksindental sampling

\section{Langkah Analis}

Adapun langkah analisis[12] pada penelitian ini adalah:

1. Merancang model struktural untuk mendefinisikan hubungan antar variabel laten.

2. Merancang model pengukuran untuk mendefinisikan hubungan antara variabel laten dengan indikatornya

3. Mengkonstruksi diagram jalur berdasarkan model structural dan model pengukuran.

4. Mengkonversikan diagram jalur ke dalam sistem persamaan.

5. Mengestimasi parameter. 
6. GoF Test.

7. Menguji hipotesis dengan menggunakan statistik uji $\mathrm{t}$ untuk mengetahui adanya hubungan antara laten eksogen dengan laten endogen dan antar laten endogen

8. Memperoleh hasil

\section{HASIL}

\section{Mengukur Kebaikan Model}

\section{Nilai Faktor Loading}

Nilai faktor loading setiap indikator terhadap konstruknya dapat dilihat pada Tabel 4.1. Nilai faktor loading dari setiap indikator dinyatakan valid apabila memiliki nilai lebih dari 0,7 .

\begin{tabular}{ccc}
\multicolumn{3}{c}{ Tabel 4.1 Nilai Faktor Loading } \\
\hline \multirow{3}{*}{ Dimensi } & Variabel & $\begin{array}{c}\text { Nilai Faktor } \\
\text { Loading }\end{array}$ \\
\hline \multirow{3}{*}{ Sistem } & $\mathrm{X}_{1}$ & 0,755 \\
& $\mathrm{X}_{2}$ & 0,773 \\
& $\mathrm{X}_{3}$ & 0,737 \\
\hline \multirow{5}{*}{ Informasi } & $\mathrm{X}_{4}$ & 0,781 \\
& $\mathrm{X}_{5}$ & 0,801 \\
& $\mathrm{X}_{6}$ & 0,715 \\
& $\mathrm{X}_{7}$ & 0,789 \\
\hline \multirow{3}{*}{ Interaksi } & $\mathrm{X}_{8}$ & 0,712 \\
& $\mathrm{X}_{9}$ & 0,805 \\
& $\mathrm{X}_{10}$ & 0,836 \\
\hline \multirow{3}{*}{ Pelayanan } & $\mathrm{X}_{11}$ & 0,708 \\
& $\mathrm{X}_{12}$ & 0,828 \\
& $\mathrm{X}_{13}$ & 0,823 \\
\hline \multirow{3}{*}{ Kepuasan } & $\mathrm{Y}_{1}$ & 0,809 \\
& $\mathrm{Y}_{2}$ & 0,875 \\
& $\mathrm{Y}_{3}$ & 0,862 \\
\hline
\end{tabular}

Berdasarkan Tabel 4.1, nilai faktor loading dari masing-masing indikator lebih dari 0,7. Sehingga dapat disimpulkan bahwa kemampuan dari setiap indikator dalam menjelaskan variabel latennya adalah valid.

\section{Nilai AVE}

Tabel 4.2 Uji Validitas Berdasarkan AVE

\begin{tabular}{ll}
\hline Variabel & AVE \\
\hline Sistem & 0,58 \\
Informasi & 0,597 \\
Interaksi & 0,618 \\
Pelayanan & 0,619 \\
Kepuasan Pengguna & 0,722 \\
\hline
\end{tabular}

Validitas konvergen dinyatakan valid apabila nilai AVE lebih dari 0,5. Penelitian menunjukan nilai AVE dari setiap variabel > 0,5 sehingga dapat disimpulkan bahwa kemampuan setiap indikator dalam menjelaskan variabel latennya adalah valid.

\section{Nilai Cross Loading}

Nilai cross loading digunakan untuk menguji validitas diskriminan pada tataran indikator dengan ketentuan bahwa korelasi antara indikator dengan variabel latennya lebih besar dari korelasi antara indikator dengan variabel laten lainnnya (diluar bloknya).

Peneltian yang dilakukan menunjukan bahwa nilai cross loading atau nilai korelasi setiap indikator terhadap variabel latennya memiliki nilai korelasi yang tinggi jika dibandingkan dengan variabel laten yang lain. Dapat dilihat pada table 4.3

\section{Mengukur Reliabilitas Indikator}

Nilai realibilitas indikator diukur dengan memperhatikan nilai composite reliability atau nilai the Dillon-Goldstein's rhos[8] sebagaimana ditunjukan dalam Tabel 4.3 sebagai berikut:

Tabel 4.3 Nilai Composite Reliability Variabel

Laten Composite Reliability

\begin{tabular}{cc}
\hline Sistem & 0,806 \\
Informasi & 0,855 \\
Interaksi & 0,832 \\
Pelayanan & 0,831 \\
Kepuasan & 0,886 \\
\hline
\end{tabular}

Berdasarkan Tabel 4.3, diperoleh nilai composite reability setiap variabel laten $>$ 0,7 sehingga dapat disimpulkan bahwa reliabilitas telah terpenuhi.

Berdasarkan hasil uji validitas dan reabilitas, diperoleh kesimpulan bahwa model semua variabel teramati adalah valid sebagai indikator dalam mengukur variabel latennya dan reabilitas model pengukurannya baik.

\section{Pengujian Inner Model}

Pengujian hipotesis Inner Model variabel laten eksogen terhadap variabel laten dapat dilihat pada Tabel 4.4. 
Tabel 4.3 Nilai Composite Reliability

\begin{tabular}{l|c|cccc}
\hline & \multicolumn{1}{c}{ Sistem } & Informasi & Interaksi & Pelayanan & Kepuasan \\
\hline $\mathrm{X}_{1}$ & 0,775 & 0,420 & 0,446 & 0,502 & 0,526 \\
$\mathrm{X}_{2}$ & 0,773 & 0,431 & 0,465 & 0,453 & 0,476 \\
$\mathrm{X}_{3}$ & 0,735 & 0,445 & 0,487 & 0,465 & 0,505 \\
$\mathrm{X}_{4}$ & 0,398 & 0,781 & 0,482 & 0,492 & 0,526 \\
$\mathrm{X}_{5}$ & 0,485 & 0,801 & 0,520 & 0,497 & 0,562 \\
$\mathrm{X}_{6}$ & 0,474 & 0,715 & 0,509 & 0,469 & 0,480 \\
$\mathrm{X}_{7}$ & 0,397 & 0,89 & 0,472 & 0,501 & 0,522 \\
$\mathrm{X}_{8}$ & 0,392 & 0,407 & 0,712 & 0,371 & 0,399 \\
$\mathrm{X}_{9}$ & 0,513 & 0,513 & 0,805 & 0,537 & 0,470 \\
$\mathrm{X}_{10}$ & 0,524 & 0,571 & 0,837 & 0,548 & 0,627 \\
$\mathrm{X}_{11}$ & 0,445 & 0,436 & 0,410 & 0,702 & 0,423 \\
$\mathrm{X}_{12}$ & 0,507 & 0,508 & 0,499 & 0,828 & 0,576 \\
$\mathrm{X}_{13}$ & 0,517 & 0,546 & 0,557 & 0,824 & 0,594 \\
$\mathrm{Y}_{1}$ & 0,568 & 0,505 & 0,534 & 0,560 & 0,810 \\
$\mathrm{Y}_{2}$ & 0,579 & 0,594 & 0,581 & 0,570 & 0,875 \\
$\mathrm{Y}_{3}$ & 0,538 & 0,626 & 0,545 & 0,612 & 0,863 \\
\hline
\end{tabular}

Hipotesis Statisti Uji t-student:

$$
H_{0}: \gamma_{1}=0 \text { melawan } H_{1}: \gamma_{1} \neq 0
$$

Tabel 4.4 Pengujian Hipotesis Inner Model

\begin{tabular}{llll}
\hline Variabel & $\begin{array}{l}\text { Hipotesis } \\
\text { Statistik }\end{array}$ & $\begin{array}{l}\mathrm{T} \text { - } \\
\text { value }\end{array}$ & $\begin{array}{l}\text { Keputusa } \\
\mathrm{n}\end{array}$ \\
\hline $\begin{array}{l}\text { Sistem -> } \\
\text { Kepuasan }\end{array}$ & $\begin{array}{l}H_{0}: \gamma_{1}=0 \\
H_{1}: \gamma_{1} \neq 0\end{array}$ & 5.74 & Tolak $\mathrm{H}_{0}$ \\
$\begin{array}{l}\text { Pengguna } \\
\text { Informasi - }\end{array}$ & $H_{0}: \gamma_{2}=0$ & & \\
$>$ Kepuasan & $H_{1}: \gamma_{2} \neq 0$ & 6.08 & Tolak $\mathrm{H}_{0}$ \\
Pengguna & & & \\
$\begin{array}{l}\text { Interaksi -> } \\
\text { Kepuasan }\end{array}$ & $H_{0}: \gamma_{3}=0$ & & \\
$\begin{array}{l}\text { Pengguna } \\
H_{1}: \gamma_{3} \neq 0\end{array}$ & 3.74 & Tolak $\mathrm{H}_{0}$ \\
Pelayanan - & $H_{0}: \gamma_{4}=0$ & & \\
$>$ Kepuasan & $H_{1}: \gamma_{4} \neq 0$ & 5.58 & Tolak $\mathrm{H}_{0}$ \\
Pengguna & & & \\
\hline
\end{tabular}

\section{Pengaruh Langsung}

Nilai pengaruh langsung dapat dilihat pada Tabel 4.5 berikut :

Tabel 4.5 Pengaruh Langsung Setiap Konstruk

\begin{tabular}{cc}
\hline Variabel Laten & Kepuasan \\
\hline Sistem & 0,247 \\
Informasi & 0,270 \\
Interaksi & 0,169 \\
Pelayanan & 0,253 \\
\hline
\end{tabular}

Dalam penelitian ini terdapat empat variabel yang memiliki pengaruh langsung terhadap kepuasan pengguna.

\section{PEMBAHASAN}

\section{Pengaruh Dimensi Sistem terhadap Kepuasan Mahasiswa}

Berdasarkan hasil uji hipotesis yang telah dilakukan diperoleh kesimpulan bahwa dimensi Informasi berpengaruh terhadap kepuasan penggunga. Dimensi sistem berpengaruh sebesar 0,247 . Nilai faktor dari masing-masing indikator valid. Nilai faktor loading terbesar ada pada variabel $x_{1}$ (kemudahan website untuk dioperasikan) sebesar 0,775 .

\section{Pengaruh Dimensi Informasi terhadap Kepuasan Mahasiswa}

Berdasarkan hasil uji hipotesis yang telah dilakukan diperoleh kesimpulan bahwa dimensi Informasi berpengaruh terhadap kepuasan penggunga. Dimensi informasi memiliki pengaruh secara langsung sebesar 0,27. Nilai faktor loading telah teruji valid. Nilai faktor loading terbesar pada dimensi ini adalah variabel $x_{5}$ ( Ketepatan waktu informasi) sebesar 0,801. 
Pengaruh Dimensi Inetraksi terhadap Kepuasan Mahasiswa

Berdasarkan hasil uji hipotesis yang telah dilakukan diperoleh kesimpulan bahwa dimensi interaksi berpengaruh terhadap kepuasan penggunga. Dimensi informasi memiliki pengaruh secara langsung sebesar 0,170 . Nilai faktor loading telah teruji valid. Nilai faktor loading terbesar pada dimensi ini adalah variabel $x_{10}$ ( kemudahan website terhubung dengan tautan lain) sebesar 0,837.

\section{Pengaruh Dimensi Pelayanan terhadap Kepuasan Mahasiswa}

Berdasarkan hasil uji hipotesis yang telah dilakukan diperoleh kesimpulan bahwa dimensi pelayanan berpengaruh terhadap kepuasan penggunga. Dimensi sistem berpengaruh sebesar 0,253 . Nilai faktor dari masing-masing indikator valid. Nilai faktor loading terbesar ada pada variabel $x_{12}$ (kemudahan dalam pengsian herreg) sebesar 0,826 .

Model akhri Penelitian dapat dilihat pada gambar 4.1

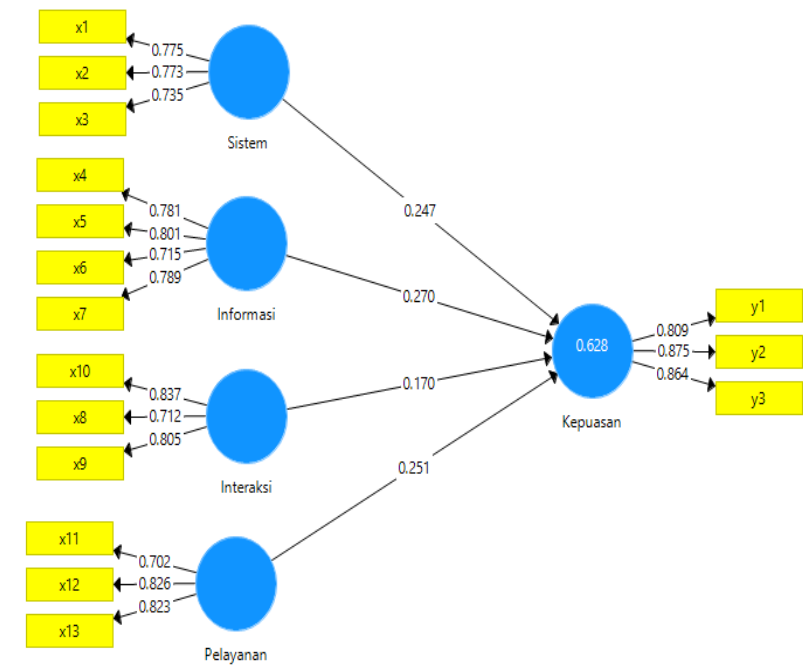

Gambar 4.1 Model Akhir Penelitian

\section{KESIMPULAN}

Berdasarkan pembahsan hasil penelitian diperoleh indikator-indikator dari dimensi sistem yaitu (1) kemudahan website dioperasikan, (2) tampilan website dan (3) kemudahan website untuk diakses signifikan serta (4) dimensi sistem berpengaruh terhadap kepuasan pengguna dengan nilai koefisien jalur sebesar 0,247. Dimensi informasi memiliki pengaruh paling tinggi dibandingkan dimensi lainnya terhadap kepuasan pengguna dengan nilai koefisien jalur sebesar 0,270 serta seluruh indikatornya signifikan terhadap informasi. Dimensi interaksi memiliki pengaruh paling rendah terhadap kepuasan pengguna dengan nilai koefisien jalur sebesar 0,170 serta seluruh indikatornya signifikan. Dimensi pelayanan signifikan berpengaruh terhadap kepuasan dengan nilai koefisien jalur sebesar 0,253 dengan model matematika sebagai berikut

$\kappa=0.247 \imath_{1}+0.2690 t_{2}+0.16890 t_{3}+0.253 t_{4}$

\section{DAFTAR PUSTAKA}

[1] Sasongko, Enngar Nur Mustafid dan Agus Rusgiono. Penerapan Metode Structural Equation Modeling untuk Analisis Kepuasan Pengguna Sistem Informasi Akademik terhadap Kualitas Website (Studi Kasus pada Website sia.undip.ac.id. Vol 5 No.3, 2016

[2] Monalisa, Siti. Analisis Kualitas Layanan Website Tehadap Kepuasan Mahasiswa dengan Penerapan Metode Webqual (Studi Kasus: UIN Suska Riau). Vol 13 No.2, 2016

[3] Suaryana, I Gusti Ngurah Agung dkk. Kualitas dan Kepuasan Pengguna Terhadap Sistem Informasi Akademik Berbasis Web. Vol 11 No. 2. 2016

[4] Pratama, Irianto Bunga. Analisis Kepuasan Pengguna pada Situs Gotomalls.com Menggunakan Metode Webqual. Tesis (Surabaya: Institut Teknologi Sepuluh November 2017)

[5] Anuraga, Gangga dan Bambang Widjanarko Otok. Pemodelan Kemiskinan Di Jawa Timur dengan Structural Equation Modeling-Partial Least Square. Vol. 1 No.2, 2013

[6] Sauddin, Adnan. Permodelan Persamaan truktural dengan Partial Least Square pada Derajat Kesejahteraan Provinsi Sulawesi Selatan (Strudi Kasus INKERA 
Provinsi Sulawesi Selatan 2014 Jurnal MSA 3, No.2 ISSN:2355-083X

[7] Narimawati, Umi dan Jonathan Sarwono. Struqtural Equation Modeling (SEM) . Jakarta : Salemba Empat, 2017

[8] Sarwono Jonathan dan Umi Narimawati. Membuat Skripsi, Tesis, dan Disertasi dengan Partial Least Square SEM (PLS SEM).Yogyakarta : Andi Offset, 2015

[9] Melita, Rosa Nur dkk. Structural Equation Modelling Dengan Pendekatan Partial Least Square (Studi Kasus: Pengaruh Locus of Control, Self Efficacy, dan Lingkungan Kerja Terhadap Kinerja Karyawan Kaltim Post Samarinda). Vol. 1 No. 1, 2016 ISSN:2528-0988.

[10] E F Haqka et al 2020. Modeling the relationship of factors that shaped student's loyalty. J. Phys.: Conf. Ser. 1442012036.

[11] M N Pratiwi et al 2020. Analysis of satisfaction and loyalty level of online taxi bike customer. J. Phys.: Conf. Ser. 1442012029

[12] I Joseph F. Hair, Jr. ... [et al.]., A primer on partial least squares structural equation modeling ( PLS-SEM) ISBN 978-1-4522-1744-4 (pbk.) Publisher: Sage Publications. 2014

[13] Schumacker, Randall E. 2010. A beginner's Guide to Structural Equation Modeling. $3^{\text {rd }}$. Taylor and Francis Group, LLC

[14] Raykov, Tenko; Marcoulides, George A. 2000. A First Course in Structural Equation Modeling. Lawrence Erlbaum Associates, Inc.

[15] Vincenzo Esposito Vinzi, Wynne W. Chin, Jörg Henseler, Huiwen. Wang 2010. Handbook of Partial Least Squares-Concepts, Methods and Applications. Springer. New York 